\title{
Increasing Autopsy Rates at a Public Hospital
}

\author{
Victor L. Souza, MD, Fred Rosner, MD
}

\begin{abstract}
Despite the acknowledged value of autopsies, autopsy rates are low in American hospitals. We developed an extensive intervention to increase the autopsy rate on the medical service of our urban teaching hospital and to identify obstacles to obtaining permission for autopsy. The 6-month intervention increased the autopsy rate from $7.5 \%$ during the previous 2 years to $16.8 \%$, but this effect disappeared after the intervention. Among patients for whom permission for autopsy was not obtained, physicians failed to request permission for $31 \%$ and families refused permission for $69 \%$.
\end{abstract}

KEY WORDS: autopsy; autopsy rate; permission for autopsy; public hospitals.

J GEN INTERN MED 1997;12:315-317.

A utopsy rates in the United States have steadily declined from $50 \%$ in the 1940 s to $10 \%$ in the 1980 s. $^{1,2}$ Several protocols have been proposed to increase autopsy rates. ${ }^{2-6}$ To increase the autopsy rate on the medical service of a public hospital, we developed and implemented an intervention that involved training resident physicians in requesting permission for autopsy, an autopsy questionnaire filled out by the doctor signing the death certificate, and follow-up of all deaths by the chief medical resident. We also identified the difficulties encountered in obtaining autopsy content.

\section{METHODS}

The study was conducted on the medical service of Gueens Hospital Center, a 350-bed public teaching hospital affiliated with the Mount Sinai School of Medicine. Resident physicians under attending physician supervision were primarily responsible for patients and interaction with patient families. To increase the autopsy rate, an intervention was designed and implemented for 6 months, beginning in January, 1995. The intervention had three parts. First, junior and senior medical residents were trained in a 2-hour didactic session about how to request permission for autopsy respectfully and informatively from family members. The training emphasized the facts that the costs of autopsy do not accrue to the family, the delay of funeral services is minimal, and the autopsy results may be important to family members and would be communicated to them. Second, physicians complet-

Received from the Department of Medicine, Mount Sinai Services at Gueens Hospital Center, Jamaica, NY (VLS, FR), and Mount Sinai School of Medicine, New York, NY (FR).

Address correspondence and reprint requests to Dr. Rosner: Queens Hospital Center, 82-68 164 St., Jamaica, NY 11432. ing death certificates for patients not undergoing autopsy were required to complete a questionnaire inquiring about why permission for autopsy was not received. Third, the medical records of all patients who died were reviewed by the chief medical resident, who attempted to obtain permission for autopsy when it had not already been obtained.

The numbers of deaths and autopsies on the medical service were determined for the 2 years before the intervention and for the 6 months after the intervention was completed. Differences in autopsy rates were tested using the $\chi^{2}$ statistic. Causes of death were determined by autopsy or by review of medical records of patients who did not undergo autopsy. Reasons why an autopsy was not performed were determined by review of the questionnaire completed by the physician certifying death, supplemented when necessary by the chief medical resident's interview of the physicians caring for the patient or of a family member. Reasons why an autopsy was not performed were classified as those describing why the family denied permission for autopsy and those describing why the family was not asked for permission.

\section{RESULTS}

During the intervention period, 101 patients on the medical service died and 17 autopsies were performed. Thus, the autopsy rate was $16.8 \%$, compared with rates between $6.2 \%$ and $8.6 \%$ during the four 6 -month periods before the intervention (Table 1). After the intervention, the autopsy rate fell to $7 \%$.

Among the 101 patients who died during the intervention period, the causes of death were acquired immunodeficiency syndrome $(n=24)$, cancer $(n=24)$, cardiopulmonary disease $(n=21)$, sepsis $(n=16)$, gastrointestinal disease $(n=5)$, hematologic disease $(n=5)$, neurologic disease $(n=4)$, renal disease $(n=1)$, and an acute abdominal process $(n=1)$. The autopsy rate did not differ significantly $(p=.3)$ among patients with different causes of death.

Among the 84 patients who did not undergo autopsy during the intervention period, permission for autopsy was denied by the family in 58 cases (69\%; Table 2). Most often, the families denied permission without giving a specific reason (27 cases). Despite the intervention, families often denied permission for autopsy because they believed they knew the cause of death ( 14 cases) or because of concern about delay in funeral services (8 cases). In 26 cases (31\%), permission for autopsy was not sought by a physician, most often because the patient was "do not resuscitate" (11 cases) or because the physicians believed they already knew the cause of death (8 cases). 
Table 1. The Autopsy Rate During the Intervention Period Compared with Periods Before and After the Intervention*

\begin{tabular}{|c|c|c|c|c|c|c|c|}
\hline & \multicolumn{4}{|c|}{ Before } & $\frac{\text { Intervention }}{1 / 95-6 / 95}$ & $\frac{\text { After }}{7 / 95-12 / 95}$ & $p$ Value \\
\hline Deaths, $n$ & 160 & 154 & 128 & 120 & 101 & 100 & - \\
\hline Autopsy rate, $\%$ & 6.2 & 7.1 & 8.6 & 8.3 & 16.8 & 7.0 & $<.001$ \\
\hline
\end{tabular}

*The time periods should be 6-month periods to be comparable to the intervention period.

\section{DISCUSSION}

We confirmed previous studies showing that a concerted effort by senior housestaff (in our study, the chief resident) and committed attending physicians can increase autopsy rates, even in municipal teaching hospitals. ${ }^{2-6}$ Maintaining a reasonable autopsy rate is important because autopsies continue to yield clinically relevant findings that are vital to ensuring the quality of medical care. ${ }^{1,7-9}$ Accordingly, the Residency Review Committee for Internal Medicine has established a $15 \%$ autopsy rate as the minimum standard-a level that was achieved during our intervention but is not achieved by half of all internal medicine residency programs reviewed for accreditation. ${ }^{8}$

The effect of our intervention, however, was modest and short-lived: the autopsy rate increased from an average rate of $7.5 \%$ to $17 \%$ during the intervention period and fell to $7 \%$ during the 6 months after the intervention. We identified and enumerated specific difficulties in attempting to increase the autopsy rate. Some of these difficulties relate to the fact that many of our patients come from low socioeconomic environments, have limited formal education, have no private physicians, and come to the municipal hospital as a last resort. Many are uninsured or illegal aliens. Some have no family or telephone at home. In this setting, it is not infrequent for family members to be unreachable immediately after a patient's death.
Our findings suggest that doctors can make a substantial difference in obtaining consent for autopsy by clarifying and dispelling myths, taboos, and simply wrong impressions about autopsies. Families should be told that the deceased will not be disfigured by autopsy and that there is no cost to the family. Concerns about delays in funeral services can be alleviated by expediting the autopsy through good communication between clinicians and pathologists. At times, junior medical residents were reluctant to ask for autopsy consent because the patient had an obvious incurable, irreversible, terminal disease and a do not resuscitate order in the chart. Do not resuscitate orders should not preclude autopsies, however, because the putative cause of death can be confirmed or denied by autopsy. Despite the significant advances in laboratory tests, imaging procedures, and endoscopic techniques, autopsies continue to reveal major unexpected findings in $10 \%$ to $20 \%$ of cases. ${ }^{7,9}$

In conclusion, autopsy remains an important diagnostic tool. We and others have shown that autopsy rates are significantly higher during periods of intense effort and follow-up of deaths with family members, even if it takes days to contact the family. The process of obtaining autopsy consent is filled with obstacles that may cause physicians to find excuses for not seeking consent. Family members may refuse consent because they did not receive an apropriate explanation of autopsy. These obstacles can often be overcome if the interest of resident physicians in

Table 2. Reasons Why Permission for Autopsy Was Not Obtained During the Intervention Period

\begin{tabular}{|c|c|}
\hline & Patients, $n(\%)$ \\
\hline All patients for whom permission for autopsy was not obtained & $84(100)$ \\
\hline The family denied permission for autopsy & $58(69)$ \\
\hline No reason given & 27 \\
\hline Because the cause of death was believed to be known & 14 \\
\hline Because of concern about delay in funeral services & 8 \\
\hline Because of disagreement among family members & 4 \\
\hline Because the body needed to be moved to another country & 3 \\
\hline Because of misunderstanding about what autopsy entails & 2 \\
\hline A physician did not request permission for autopsy & $26(31)$ \\
\hline Because the patient was "do not resuscitate" & 11 \\
\hline Because the cause of death was believed to be known & 8 \\
\hline Because a family member could not be found & 5 \\
\hline Because the physician feared malpractice litigation & 2 \\
\hline
\end{tabular}


seeking permission for autopsy is maintained, if autopsy is explained well to family members, and if autopsy is available without delay. To overcome these obstacles and increase the autopsy rate, clinicians and pathologists need to concentrate and coordinate their efforts to improve the process of obtaining autopsy consent.

\section{REFERENCES}

1. Anderson RE, Hill RB. The autopsy in academic medical centers in the United States. Hum Pathol. 1988;19:1369-71.

2. Brooks JP, Dempsey J. How can hospital autopsy rates be increased? Arch Pathol Lab Med. 1991;115:1107-11.
3. Clayton SA, Sivak SL. Improving the autopsy rate at a university hospital. Am J Med. 1992;92:423-6.

4. Smith RD, Zumwalt RE. One department's experience with increasing the autopsy rate. Arch Pathol Lab Med. 1984;108:455-7.

5. Soubani AO, Mir T, Khan FA. Improving autopsy rate in a teaching hospital. Am J Med. 1995;98:418-9.

6. Djaldetti M, Hart J, Yarmolovsky A, et al. Is it possible to improve the autopsy rate? Isr $J$ Med Sci. 1995;31:436-8.

7. Landefeld CS, Chren MM, Myers A, Geller R, Robbins S, Goldman L. Diagnostic yield of the autopsy in a university hospital and a community hospital. N Engl J Med. 1988;318:1249-54.

8. Schatz IJ. Internal medicine residency program violations of the minimum autopsy rate. JAMA. 1995;273:1092.

9. Goldman L, Sayson R, Robbins S, Cohn LH, Bettman M, Weisberg $M$. The value of the autopsy in three medical areas. N Engl $J$ Med. 1983;308:1000-5.

\section{JGIM's E-mail Address}

For Letters to the Editor or for information about submitting manuscripts to JGIM: Walklett@mail.med.upenn.edu 